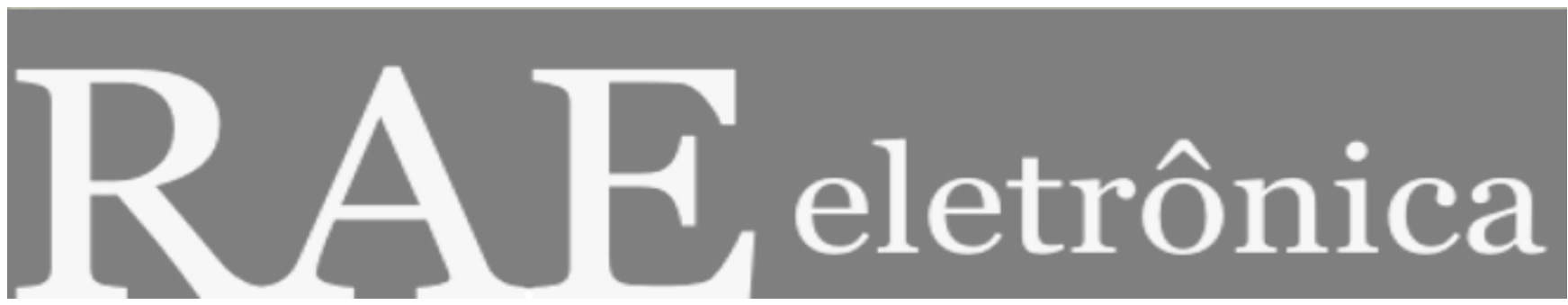

\title{
ÉTICA EMPRESARIAL: RESPONSABILIDADE GLOBAL E GERENCIAMENTO MODERNO
}

Por

Sérgio Luís Boeira

RAE-eletrônica, Volume 2, Número 1, jan-jun/2003.

http://www.rae.com.br/eletronica/index.cfm?FuseAction=Artigo \&ID $=1514 \&$ Secao=RESENHAS \&Volume $=2 \&$ Numero $=1$ $\& A n o=2003$

CCopyright, 2002, RAE-eletrônica. Todos os direitos, inclusive de tradução, são reservados. É permitido citar parte de artigos sem autorização prévia desde que seja identificada a fonte. A reprodução total de artigos é proibida. Os artigos só devem ser usados para uso pessoal e nãocomercial. Em caso de dúvidas, consulte a redação: redacao@rae.com.br.

A RAE-eletrônica é a revista on-line da FGV-EAESP, totalmente aberta e criada com o objetivo de agilizar a veiculação de trabalhos inéditos. Lançada em janeiro de 2002, com perfil acadêmico, é dedicada a professores, pesquisadores e estudantes. Para mais informações consulte o site www.rae.com.br/eletronica.

RAE-eletrônica

ISSN 1676-5648

(C)2002 Editora: Fundação Getulio Vargas - Escola de Administração de Empresas de São Paulo.

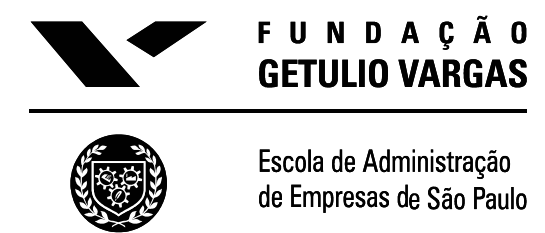




\section{ÉTICA EMPRESARIAL: RESPONSABILIDADE GLOBAL E GERENCIAMENTO MODERNO}

\section{Por Sérgio Luís Boeira,}

Doutor em Ciências Humanas (UFSC) e professor da Universidade do Vale do Itajaí (UNIVALI)

E-mail: slboeira@brturbo.com

Ética empresarial: responsabilidade global e gerenciamento moderno

De Klaus M. Leisinger \& Karin Schmitt

Petrópolis, Vozes, 2001, 231 p.

Klaus Leisinger e sua colaboradora Karin Schmitt elaboram uma argumentação consistente e perspicaz numa das obras mais bem documentadas entre as disponíveis no mercado editorial brasileiro, no que se refere à ética e responsabilidade empresariais. Leisinger é professor de sociologia do desenvolvimento na Universidade de Basiléia (Suíça) e coordenador da Fundação Novartis para o desenvolvimento sustentável. É considerado um dos maiores especialistas em demografia mundial.

O livro é dividido em três partes, cada uma delas com diversos capítulos. A primeira é intitulada Ética empresarial: o que é, o que pretende. Trata da suspeita que ronda o mundo empresarial, do enfoque dos executivos sobre eles próprios e da situação das empresas multinacionais nos países "em desenvolvimento". A segunda parte é intitulada Fiduciários da moral. Os autores contestam os que afirmam (como os neoliberais) ser a liberdade de todos os participantes do processo econômico a única garantia para o bem-estar do povo, ou que para isso seja suficiente obedecer às leis em vigor. Tentam demonstrar que "por si sós nem o mercado nem a lei têm como conseqüência necessária a obediência moral às exigências sociais e ecológicas" (p. 41). Tratam também da relação entre direitos humanos e empresas estrangeiras, a partir de problemas concretos; discutem e definem o que é corrupção, seus tipos e conseqüências destrutivas em larga escala, além de refletir sobre como o fenômeno poderia ser combatido. Ainda nesta parte, os autores tratam da problemática do meio ambiente, demonstrando o quanto a defesa deste integra-se à noção de responsabilidade social e à idéia de estratégia empresarial. Por fim, a terceira parte é intitulada Empresa ética: orientações para principiantes, título, aliás, que é mais adequado aos leitores europeus e norte-americanos (mais familiarizados com a temática) do que ao brasileiro. No Brasil, esta obra é recomendada a universitários e empresários com perfil críticoanalítico, já que consistentemente exige reflexão e apresenta argumentos sutis sobre uma temática das mais complexas. Os capítulos desta última parte tratam dos shareholder values e dos stakeholder values, dos limites da responsabilidade das empresas, de como formular e implementar normas empresariais, além de discutir as desvantagens destas, os pressupostos para um diálogo fecundo dentro das organizações (e também os limites práticos do diálogo). A obra aborda também a crítica vinda "de dentro" das empresas (suas formas, e como tratá-las), a importância da ética individual e da personalidade de liderança (e não de meros especialistas). Aprofundando este último aspecto, os autores discutem a personalidade do chefe "ideal", convívio com o poder e o desenvolvimento pessoal integral. Por último, tratam da relação entre moral e capital, sustentando que aquela atrai este (pelo menos no longo prazo), e apresentam uma síntese de seus argumentos relativamente a clientes, empregados, investidores, fornecedores e parceiros, empresas concorrentes e à sociedade em geral.

Feita esta apresentação, abordaremos agora os conceitos iniciais da obra. Já no prefácio à edição alemã, Leisinger observa que até os anos 50 o conceito de "ética empresarial" ainda não havia entrado no vocabulário acadêmico. Os aspectos morais das atividades econômicas estavam submetidos a uma espécie de ética social que fazia referência à “questão trabalhista". Porém, no final da década de 1960 
as relações entre economia e sociedade chegaram a atingir um público mais amplo: além dos direitos dos trabalhadores, entraram em foco os direitos das minorias, das mulheres, o direito ambiental, as questões de saúde e segurança e a preocupação com os países em desenvolvimento. "Tudo isto cabe hoje na rubrica da ética empresarial", afirma Leisinger, apontando o crescente interesse internacional, os inúmeros livros, revistas, seminários, simpósios, cátedras e organizações em torno da ética. Desde meados dos anos 70 todo agir socialmente relevante tem sido submetido a uma reflexão deste tipo e por isso surgiram rótulos como "ética ambiental", "ética da mídia", "ética da pesquisa" - e com eles também o de "ética empresarial".

É um fato também que nesta temática a quantidade de palavras não conduz necessariamente à qualidade, podendo mesmo encobri-la. O resultado de um tal convívio com a ética pode ser uma nausea ethica, um "nojo da ética". Leisinger cita Ursula Pia Jauch, para quem "onde se fala muito de ética, a força dos argumentos é pequena e duvidosa a consistência moral real das pessoas" (p.14). Para ela, o uso inflacionário da palavra "ética" pode ser interpretado como sinal de um argumento político para se vender algo, de um exercício de álibi científico, de uma retórica empresarial de segurança.

É preciso avançar com cuidado, portanto. Na linguagem coloquial, há mais de dois mil anos os conceitos de moral e de ética são em grande medida usados como sinônimos, apesar de não o serem. Por moral entendem os autores determinadas normas que orientam o comportamento prático (sobretudo para com o próximo, mas também para com a natureza e para consigo mesmo). A ética, como ciência ou parte da filosofia (há controvérsias na literatura sobre esta dicotomia), ocupa-se com o tema de uma maneira descritiva e comparativa, mas também como uma avaliação crítica da moral.

A moral se manifesta quando determinada conduta humana é considera "boa" ou "má", o que revela um valor ou desvalor e permite concluir-se que a moral é orientada por valores. Porém, o que caracteriza essencialmente a moral é que "ela pretende intervir orientando e mostrando a direção antes que uma determinada ação seja concretizada" (p.18). Isto significa que há exigências pelas quais a moral adquire seu caráter normativo. As normas já pressupõem os valores - aquelas exigem a realização destes. As normas, no entanto, só funcionam enquanto e na medida em que se apresentam como evidentes para o indivíduo. Quando exigimos alguma coisa que para o outro não é evidente ficamos na situação de ter que justificar a exigência. Com freqüência as controvérsias éticas ocorrem pelo fato de os parceiros não compartilharem os valores sobre os quais fundamentam suas normas morais. O que para um representa um valor para outro pode representar um desvalor. Os autores postulam (apoiados em Victor Kraft) que a atribuição de valores pela pessoa ou pela sociedade tem que ser uma tomada de posição em relação a determinados bens numa determinada situação, do contrário a moral se transforma em "moralismo", que na realidade trivializa tudo quanto é moral. "O moralismo reduz a ética a banalidades, transforma a vida moral em assunto de trivial importância. Ele amputa radicalmente a complexidade da ética, reduzindo-a a dimensões manipuláveis de pequenez moral, capaz de ser reduzida a um código, cujo seguimento tranqüiliza a consciência" (p.19). Esta crítica enfatiza uma diferença relevante entre o enfoque desta obra e o de outras do mesmo campo de estudo.

Por fim, cabe destacar que para os autores a ética empresarial "tende ao bem mais amplo de todas as pessoas - e para isto é necessário que sejam satisfeitos os objetivos econômicos, pois do contrário ela não poderia cumprir sua finalidade humana" (p.183). Embora falte um tratamento mais sistemático e profundo das relações entre ética, política, economia e ciência (debate sobre crise de paradigmas, sobre modernidade e pós-modernidade ou sobre as várias dimensões da globalização), a obra tem importante contribuição no sentido de relacionar aspectos macro e microculturais da vida empresarial, especialmente em função da perspicácia psicológica e da experiência profissional dos autores. 